\title{
Parental Financial Education During Childhood and Financial Behaviors of Emerging Adults
}

\author{
Ashley B. LeBaron \\ University of Arizona \\ Erin K. Holmes \\ Brigham Young University - Provo, erin_holmes@byu.edu \\ Bryce L. Jorgensen \\ New Mexico State University \\ Roy A. Bean \\ Brigham Young University - Provo
}

Follow this and additional works at: https://scholarsarchive.byu.edu/facpub

Part of the Other Social and Behavioral Sciences Commons

\section{Original Publication Citation}

*LeBaron, A. B., Holmes, E. K., Jorgensen, B., and Bean, R. (2020). Parental financial education during childhood and financial behaviors of emerging adults. Journal of Financial Counseling and Planning.

\section{BYU ScholarsArchive Citation}

LeBaron, Ashley B.; Holmes, Erin K.; Jorgensen, Bryce L.; and Bean, Roy A., "Parental Financial Education During Childhood and Financial Behaviors of Emerging Adults" (2020). Faculty Publications. 4781.

https://scholarsarchive.byu.edu/facpub/4781

This Peer-Reviewed Article is brought to you for free and open access by BYU ScholarsArchive. It has been accepted for inclusion in Faculty Publications by an authorized administrator of BYU ScholarsArchive. For more information, please contact ellen_amatangelo@byu.edu. 


\title{
Parental Financial Education During Childhood and Financial Behaviors of Emerging Adults
}

\author{
Ashley B. LeBaron, ${ }^{a} \odot$ Erin K. Holmes, ${ }^{b} \odot$ Bryce L. Jorgensen, ${ }^{c} \odot$ and Roy A. Bean ${ }^{d} \odot$
}

The purpose of this article was to determine whether overt financial education from parents during childhood (retrospective measure collected in the same survey wave) is associated with a greater frequency of healthy financial management behaviors in emerging adulthood, and whether this relationship is dependent on gender. Using a sample of emerging adults from the Flourishing Families dataset $(N=437)$, we ran two multivariate linear regressions - one with and one without the interaction variable. Results suggest that financial education from parents during childhood is linked with a greater frequency of healthy financial behaviors in emerging adulthood but was not dependent on gender. Financial educators should involve parents when teaching children about money, and they should educate parents on how to teach their children about money.

Keywords: emerging adults, financial behavior, financial education, financial management, financial socialization, gender

$\mathrm{F}$ inancial management, which encompasses behaviors related to consumption, cash management, savings and investment, and credit management (Dew \& Xiao, 2011), impacts the well-being of individuals, families, and societies (Clarke, Heaton, Israelsen, \& Eggett, 2005; Hira, 2012; Xiao, Chatterjee, \& Kim, 2014). Specifically, while healthy financial management engenders success and stability (Dew, 2007), unhealthy management can create stress (Britt \& Huston, 2012) and hardship (Dew, 2007, 2008). It is therefore worrisome that the financial management behaviors of today's emerging adults are largely unhealthy (FINRA Investor Education Foundation, 2013). In order to prepare future generations of emerging adults to enact healthy financial management behaviors, family financial socialization during childhood is key (GrinsteinWeiss, Spader, Yeo, Key, \& Freeze, 2012; Jorgensen \& Savla, 2010). Overt financial education (i.e., explicit and purposeful teaching of financial concepts) from parents may be a critical component of this socialization (Clarke et al., 2005; LeBaron, Hill, Rosa, \& Marks, 2018a, 2018b, 2018c). By using a distinct dataset, the current study offers needed support for the solidification of overt financial education as a crucial component of financial socialization, specifically as a predictor of future financial behaviors. The purpose of this artcle is to determine whether overt financial education during childhood is associated with frequency of healthy financial management behaviors in emerging adulthood, and whether this relationship is dependent on gender.

\section{Previous Research and Hypotheses Family Financial Socialization}

Danes (1994) defined financial socialization as "the process of acquiring and developing values, attitudes, standards, norms, knowledge, and behaviors that contribute to the financial viability and well-being of the individual" (p. 128). The family is a central component of this process of acquiring knowledge, attitudes, and capabilities related to finances (Clarke et al., 2005; Grinstein-Weiss et al., 2012; Jorgensen \& Savla, 2010), perhaps more central than school, media, and peers (Pinto, Parente, \& Mansfield,

\footnotetext{
${ }^{a}$ Doctoral Student, Family Studies and Human Development, University of Arizona, 650 N Park Ave, Norton School of Family \& Consumer Sciences, Tucson, AZ 85721-0078. E-mail: lebaronashley@gmail.com

${ }^{b}$ Associate Professor, School of Family Life, Brigham Young University, 2086D JFSB, Brigham Young University, Provo, UT 84602. E-mail: erin_holmes@byu.edu

${ }^{c}$ Assistant Professor and Family Resource Management Specialist, Extension Family and Consumer Sciences, New Mexico State University, 940 College Drive, GTH 308, Las Cruces, NM 88003.E-mail: brycej@nmsu.edu

${ }^{d}$ Professor, School of Family Life, Brigham Young University, 257 TLRB, Brigham Young University, Provo, UT 84602. E-mail: roy_bean@byu.edu
} 
2005). Indeed, Shim, Barber, Card, Xiao, and Serido (2010) found that parents' influence on emerging adults' financial knowledge, attitudes, and capabilities was greater than the influence of secondary education and work experience combined. In the family financial socialization model, Gudmunson and Danes' (2011) proposed that family financial socialization processes (i.e., personal and family characteristics, family interaction and relationships, and purposive, or intentional, financial socialization) predict financial socialization outcomes (i.e., financial attitudes, knowledge, and capabilities, financial behavior, and financial well-being). The current article follows this theoretical claim that positive financial socialization (specifically overt financial socialization) contributes to healthy financial behaviors.

Financial Education and Gender Socialization. It is important to acknowledge that financial socialization occurs in the context of other socializing practices (Gudmunson \& Danes, 2011). One important socializing practice that likely intersects with financial socialization is gender socialization. Parents contribute to gender socialization in four important ways: channeling (e.g., shaping the environment in gendered ways), differential treatment (e.g., behaving differently toward males than females), direct instruction (e.g., telling males and females to behave in different ways), and modeling (e.g., demonstrating gendered behavior for children; Blakemore, Berenbaum, \& Liben, 2013; Else-Quest \& Shibley Hyde, 2018). Based on these ideas, parents' attitudes about gender roles may impact the decisions they make about teaching males and females about finances. For example, if parents endorse traditional gender roles, they may emphasize more caregiving opportunities for daughters and emphasize more breadwinning opportunities for sons. In this scenario, it is possible that by emphasizing breadwinning opportunities for sons, parents may introduce sons to more opportunities to earn and manage money.

There is some evidence that female and male children receive different financial socialization from parents. For example, Newcomb and Rabow (1999) found that parents had higher expectations regarding working and saving for sons compared to daughters, and that parents emphasized money and grades more for sons than for daughters. Newcomb and Rabow also found that parents discussed the family's finances with sons at an earlier age than they did with daughters. This was also found in a more recent study: Agnew and Cameron-Agnew (2015) found that parent-child financial discussions began at a younger age for male children than for female children.

Unfortunately exploring differential financial socialization is still limited. Though all components of gender socialization may impact the way gendered ideas in families impact the financial socialization of children, in this article we explore overt financial education as a feature of direct instruction in families, and explore how the sex of the child in the family system may moderate associations between overt financial education and financial behaviors.

Overt Financial Education. Much of the research on family financial socialization has measured parental influence via modeling (Hibbert, Beutler, \& Martin, 2004; Rosa, Marks, LeBaron, \& Hill, 2018) and monitoring (Kim \& Chatterjee, 2013). These are important aspects of socialization and have been linked with healthy financial behaviors later in life (Jorgensen, Rappleyea, Schweichler, Fang, \& Moran, 2017b; Shim et al., 2010; Webley \& Nyhus, 2006). However, there is a need for exploration of the impact of overt financial education from parents. Overt financial education is synonymous with financial teaching, similar to that conducted in financial literacy courses. In the literature, this concept is also referred to as parent-child financial discussion (LeBaron et al., 2018a; LeBaron et al., 2018c). Recent studies suggest that parent-child financial discussion during high school is positively associated with concurrent financial knowledge (Chambers, Asarta, \& Farley-Ripple, 2019; Deenanath, Danes, \& Jang, 2019) and healthy financial behaviors (Deenanath et al., 2019). Another study found that parents' overt financial teaching during childhood was associated with less credit card debt in emerging adulthood (Norvilitis \& MacLean, 2010). Additionally, the same study suggested that lack of overt financial teaching during childhood was associated with unhealthy credit card use. Jorgensen et al. (2017b) further explored the relationship between overt financial education and financial management behaviors by measuring the frequency of a variety of financial management behaviors, not just those associated with credit. Jorgensen et al. (2017b) found that childhood financial education was indeed predictive of later financial management behaviors in emerging adults. Because research on overt financial education from parents is relatively new, it is important that this potential relationship be explored further. 
Gender. This article builds on previous research by examining the relationship between overt financial education and financial management behaviors by gender. While we introduced the possibility that parents may socialize their children differently according to the child's sex, it is also important to discuss the larger social context in which financial and gender socialization occur. A feminist theoretical perspective sensitizes finance researchers to the idea that money is both a source and manifestation of power and privilege (Meisenbach, 2010; Pahl, 1995; Rodman, 1972). Using a feminist deconstruction of power hierarchies that often result from hegemonic masculinity, males have traditionally enjoyed greater privilege and power than females (Beckman, 2014). This may be because hegemony perpetuates hierarchies of power and privilege through the creation and perpetuation of social norms and expectations (Connell \& Messerschmidt, 2005). Such norms and expectations may include the idea that finances are a man's domain (Fonseca, Mullen, Zamarro, \& Zissimopoulos, 2012; Smith, McArdle, \& Willis, 2010), and as such, it is assumed that males ought to participate more frequently in healthy financial management behaviors such as investing (Almenberg $\&$ Dreber, 2015). Scholars have found some evidence that gender differences may exist between males and females that could perpetuate these hierarchies. For example, some scholars have found that males in their samples have more financial knowledge than females (Borden, Lee, Serido, \& Collins, 2008; Chen \& Volpe, 2002; Danes \& Brewton, 2014; Fonseca et al., 2012; Lusardi \& Mitchell, 2008; Lusardi, Mitchell, \& Curto, 2010; Newcomb \& Rabow, 1999), report more confidence about finances (Chen \& Volpe, 2002; Danes \& Brewton, 2014; Newcomb \& Rabow, 1999), and choose a finance-related college major more often than females do (Johnson \& Muse, 2017). Most notably, a recent study of almost 10,000 high school students from 18 countries found that males had more financial knowledge than females (Chambers et al., 2019).

However, some literature suggests that females may have unique opportunities with finances; for example, Clarke et al. (2005) found that although children viewed fathers as the parent "most responsible for finances in the home" (p. 333), and fathers modeled financial tasks more frequently than mothers did, mothers modeled the specific financial tasks of budgeting and saving more frequently than fathers did. Additionally, families differ in their family financial management approach, and in some families the mother primarily manages funds (Pahl, 1995; Yodanis \& Lauer, 2007), indicating opportunity for females to gain financial experience in the home. It is likely that these gender differences stem from a complex combination of factors including socialization of gender norms and expectations (Wang \& Degol, 2013), hormonal differences (Sapienza, Zingales, $\&$ Maestripieri, 2009), and differing interests (Gati, Osipow, \& Givon, 1995; Wang \& Degol, 2013).

Placing overt financial socialization in a family and societal context regarding gender socialization suggests that females may have fewer financial experiences and opportunities both inside and outside the home. Thus, one's sex may interact with the parent's overt financial behavior to differentially impact a child's financial behavior. We see two possibilities for the way these may interact. One possibility suggests that parents may offer more overt financial behavior to sons than to daughters to perpetuate traditional gender role norms and hierarchies that they experience in the larger society. Another possibility suggests that parents may be an important intervening influence for the financial socialization of daughters such that when overt financial education is present in the home of daughters, it may have greater impact on daughters than sons. There is some evidence for this second possibility. For example, Jorgensen and Savla (2010) found that, according to retrospective perceptions, parents were more influential to daughter's financial learning than son's. Additionally, several studies have suggested that because males have greater financial knowledge on average, females benefit more from financial education courses (Danes \& Brewton, 2014; Danes \& Haberman, 2007). It is probable that this gendered benefit would also apply to financial education taking place within families, but more research with various samples is needed.

\section{Hypotheses}

As financial socialization research progresses, it is crucial that the outcomes of financial education be examined. The purpose of this study was to determine whether overt financial education from parents during childhood is associated with a greater frequency of healthy financial management behaviors in emerging adulthood and whether this relationship is dependent on gender. We are not familiar with any another study that has tested this relationship by gender. Overt financial education from parents may be especially 
predictive of healthy financial management behaviors for females because they receive less financial training and experiences elsewhere compared to males. We controlled for emerging adults' income, age, race, gender, materialism, and impulsivity, as well as their entitlement and their parents' income during childhood. Higher levels of materialism, impulsivity, and entitlement may engender unhealthy spending behaviors (Garðarsdóttir \& Dittmar, 2012; Watson, 2003). Emerging adults' income and parents' income may influence aspects of financial management behavior such as saving and debt (Kan \& Laurie, 2014). In terms of age, older individuals may make more mature financial decisions (Xiao, Chen, \& Sun, 2015).

In connection with the family financial socialization theoretical framework (Gudmunson \& Danes, 2011), we used overt financial education to measure purposive/intentional financial socialization and gender as a specific measure of personal characteristics, predicting financial behaviors as a specific financial socialization outcome. In terms of control variables, emerging adults' income, age, and race were measures of personal characteristics; parents' income was a measure of family characteristics; and materialism, impulsivity, and entitlement were additional financial socialization outcomes (specifically, financial attitudes). Financial attitudes such as materialism, impulsivity, and entitlement have been shown to negatively influence financial behaviors (Nye \& Hillyard, 2013).

Based on previous research and theory, we have two hypotheses:

H1: Overt financial education will be associated with a greater frequency of healthy financial management behaviors, controlling for emerging adults' income, age, race, gender, materialism, and impulsivity, as well as their entitlement and their parents' income during childhood.

H2: Gender will moderate the relationship between overt financial education and frequency of healthy financial management behaviors. Specifically, the relationship will be stronger for females.

\section{Method}

\section{Participants and Procedure}

The participants in this study came from the Flourishing Families Project, a longitudinal study of inner family life.
The purpose of the study was to identify how family processes (both positive and negative) affect the development and trajectory of children, from adolescence into emerging adulthood. Project data were collected from mothers, fathers, and children (one selected child per family) through observation and survey methods from a large northwestern city. Data was collected yearly from 2007 (wave 1) to 2016 (wave 10). Thus, in the early waves the child participants were adolescents (currently receiving financial socialization), and at wave 10 they were emerging adults (with measurable financial behavior outcomes). Originally, participants were primarily recruited using a purchased national survey database that included information about millions of households. Families were randomly selected from specified census tracts that mirrored socio-economic and racial stratification of local school districts. To include underrepresented populations, a limited number of families were recruited using flyers and referrals. Families were contacted using a multi-step method that included a letter of introduction, home visits, and phone calls. After eligibility and consent were established, interviewers conducted an in-home interview to complete the questionnaires with the families (Day, Coyne, Dyer, Harper \& Walker, 2016).

At wave 10, the sample ( $N=437$ emerging adults) had a fairly even gender split with $48.05 \%$ male and $51.95 \%$ female. In terms of race/ethnicity (measured at wave 1), $75.36 \%$ of participants were European American, 9.79\% were African American, 9.32\% were multi-ethnic, and a small percentage of participants $(5.53 \%)$ were Hispanic, Asian American, and other. There were $62.07 \%$ of emerging adult participants with an income under $\$ 10,000$ per year, likely owing to their student status. The age of participants ranged from 18 to 23, with an average age of 20.29 .

\section{Measures}

Our research question was whether overt financial education from parents during childhood/adolescence is associated with a greater frequency of healthy financial management behaviors in emerging adulthood (and whether this relationship is dependent on gender). Thus, our dependent variable (i.e., financial behaviors) was measured at wave 10. Our primary independent variable (i.e., overt financial education) was measured at wave 10 but was retrospective and was designed to capture overt financial education during childhood/adolescence. Control variables were 
not measured at all waves and were used as available and as made sense for addressing our research question.

Overt Financial Education. This item is part of a larger item, Financial Communication, which assesses how parents communicated with their children about finances during childhood/adolescence (Jorgensen et al., 2017b). This was measured in wave 10 , so it is retrospective. Respondents were asked, "How would you describe how finances were communicated in your family? (check all that apply)." One of the available options was "My parents explicitly taught me about finances (e.g., credit cards, debt, budgeting, savings)." Because respondents either checked or did not check this item, it is a dichotomous variable, with 1 meaning that they did receive overt financial education (and 0 meaning they did not).

Frequency of Healthy Financial Behaviors. For this Financial Management Behaviors scale, measured in wave 10 , participants were asked how often they engaged in various financial behaviors and responded on a 5-point Likert scale ranging from 1 (never) to 5 (always). There were seven items: "paid all your bills on time," "kept a written or electronic record of your monthly expenses," "stayed within your budget or spending plan," "paid off credit card balance in full each month," "made only minimum payments on a loan (reverse coded)," "began or maintained an emergency savings fund," and "saved money from every paycheck." These items have been validated using a nationally representative sample (Dew \& Xiao, 2011). Reliability for this construct was acceptable $(\alpha=.71)$. The mean of the seven items was used for analyses.

Gender. Measured at wave 10, gender was a dichotomous variable with 0 as male and 1 as female.

Control Variables. The Materialism scale (Carroll, 2004), measured in wave 10, is composed of four items, including "I like to have the newest products as soon as they come out." Items are on a 5-point Likert scale ranging from 1 (not at all like me) to 5 (very much like me). Reliability for this construct was acceptable $(\alpha=.76)$. The mean of the four items was used for analyses. Impulsivity was measured by reverse coding items from the Self-Regulation scale (Novak $\&$ Clayton, 2001). Data was from wave 10. The scale is composed of 12 items, including "I have a hard time controlling my temper." Items are on a 4-point Likert scale ranging from
1 (never true) to 4 (always true). Reliability for this construct was acceptable $(\alpha=.77)$. The mean of the 12 items was used for analyses. The entitlement scale (Beutler \& Gudmunson, 2012), measured in wave 2 , is composed of 10 items, including "I should be able to have the latest styles." Items are on a 5-point Likert scale ranging from 1 (strongly disagree) to 5 (strongly agree). Reliability for this construct was acceptable $(\alpha=.85)$. The mean of the 10 items was used for analyses. Income was measured on an ordinal scale ranging from 1 (under $\$ 10,000$ per year) to 12 (\$120,000 or more per year). Emerging adults' income was measured at wave 10, while parents' income was measured at wave 3. Age, measured at wave 10 , was a continuous variable ranging from 18 to 23 . Race, measured at wave 1 (not available at wave 10), was recoded so that European American $=0$, Other $=1$.

\section{Data Analysis}

To test the hypotheses, analyses were conducted in a fourstep process. First, we ran descriptive results on the study variables to better understand the variables being tested. Second, we ran preliminary bivariate correlations to gauge the relationship between the variables. Next, we ran a linear regression to test whether overt financial education was associated with healthy financial behaviors, controlling for emerging adults' income, age, race, gender, materialism, and impulsivity, as well as their entitlement and their parents' income during childhood. Finally, we ran a second regression with an interaction between gender and financial education to test gender as a moderator.

\section{Results}

\section{Descriptive Results}

Descriptive statistics for the study variables are presented in Table 1. Responses to the financial education item ranged from 0 to 1 , with a mean of 0.46 (standard deviation $[S D]=$ $0.50)$. Responses to the financial behaviors scale ranged from 0 to 5 , with a mean of $3.22(S D=1.00)$. In regards to the control variables, materialism ranged from 1 to 5 , with a mean of $2.74(S D=0.96)$; impulsivity ranged from 1 to 3.25 , with a mean of $2.01(S D=0.45)$; entitlement ranged from 1 to 4.9 , with a mean of $2.78(S D=0.66)$; emerging adult income ranged from 1 to 12 , with a mean of 2.02 ( $S D$ $=1.72$ ); parent income ranged from 1 to 12 , with a mean of $7.91(S D=3.10)$. Age, race, and gender information can be found in the "Participants and Procedure" section. 
TABLE 1. Descriptive Statistics for Study Variables $(N=437)$

\begin{tabular}{lllll}
\hline Variable & $\boldsymbol{M}$ & $\boldsymbol{S D}$ & Range & \% \\
\hline Healthy financial behaviors & 3.22 & 1.00 & $0-5$ & $0-1$ \\
Overt financial education & 0.46 & 0.50 & $1-5$ & $1-3.25$ \\
Materialism & 2.74 & 0.96 & $1-4.9$ \\
Impulsivity & 2.01 & 0.45 & $1-12$ & $1-12$ \\
Entitlement & 2.78 & 0.66 & $18-23$ & \\
Emerging adult income & 2.02 & 1.72 & & 30.43 \\
Parent income & 7.91 & 3.10 & - & \\
Age & 20.29 & 1.04 & - & 48.05 \\
Race & & & & 51.95 \\
$\quad$ European American & - & - & - & \\
$\quad$ Other & - & - & & \\
Gender & - & - & & \\
$\quad$ Male & - & - & & \\
Female & & & & \\
\hline
\end{tabular}

Note. $S D=$ standard deviation.

TABLE 2. Correlations Between Variables

\begin{tabular}{|c|c|c|c|c|c|c|c|c|c|}
\hline & 1 & 2 & 3 & 4 & 5 & 6 & 7 & 8 & 9 \\
\hline 1. Healthy financial behaviors & - & & & & & & & & \\
\hline 2. Overt financial education & $.16^{* *}$ & - & & & & & & & \\
\hline 3. Materialism & -.06 & .08 & - & & & & & & \\
\hline 4. Impulsivity & $-.20 * * *$ & $-.13 * *$ & .05 & - & & & & & \\
\hline 5. Entitlement & $-.10^{*}$ & -.04 & $.25 * * *$ & .05 & - & & & & \\
\hline 6. Emerging adult income & .06 & .05 & $.16^{* * *}$ & -.03 & .00 & - & & & \\
\hline 7. Parent income & .09 & .07 & .00 & -.03 & .00 & -.02 & - & & \\
\hline 8. Age & -.08 & -.02 & -.06 & -.07 & $.16^{* *}$ & $.16^{* * *}$ & -.06 & - & \\
\hline 9. Race (European American $=0$ ) & $-.12 *$ & $-.10^{*}$ & $.11^{*}$ & .07 & $.11^{*}$ & -.06 & $-.20 * * *$ & .05 & - \\
\hline 10. Female $($ male $=0)$ & .01 & -.05 & -.03 & .08 & .01 & -.08 & -.02 & -.06 & .03 \\
\hline
\end{tabular}

\section{Bivariate Correlations}

Pearson correlation coefficients were then run. As shown in Table 2, overt financial education was positively associated with frequency of healthy financial behaviors $(r=$ $.16, p=.001)$. Entitlement was negatively associated with frequency of healthy financial behaviors $(r=-.10, p=$ $.04)$, as was impulsivity $(r=-.20, p<.001)$. Additionally, being non-European American was negatively associated with frequency of healthy financial behaviors $(r=$ $-.12, p=.01)$. Surprisingly, none of the other control variables were significantly correlated with financial behaviors (see Table 2).

\section{Multivariate Linear Regressions}

To test the first hypothesis, we ran a linear regression to determine whether overt financial education from parents during childhood was associated with frequency of healthy financial behaviors during emerging adulthood, controlling for emerging adults' income, age, race, gender, materialism, and impulsivity, as well as their entitlement and their parents' income during childhood. This produced a significant model fit $(F(9,281)=4.83, p<.001)$ which accounted for approximately $13 \%$ of the variance in frequency of healthy financial behaviors $\left(R^{2}=.13\right.$, Adjusted $R^{2}$ $=.11)$. As seen in Table 3, results indicated that overt finan- 
TABLE 3. Linear Regression Predicting Frequency of Healthy Financial Behaviors

\begin{tabular}{|c|c|c|c|c|}
\hline & \multicolumn{2}{|c|}{ Model 1 (No Interaction) } & \multicolumn{2}{|c|}{ Model 2 (Interaction) } \\
\hline & $\beta$ & $S E$ & $\beta$ & $S E$ \\
\hline Constant & $5.82 * * *$ & 1.19 & $5.80 * * *$ & 1.19 \\
\hline Overt financial education & $.17 * *$ & .11 & $.25 * *$ & .16 \\
\hline Materialism & -.01 & .06 & -.02 & .06 \\
\hline Impulsivity & $-.25 * * *$ & .12 & $-.25 * * *$ & .12 \\
\hline Entitlement & $-.12 *$ & .10 & $-.12 *$ & .10 \\
\hline Emerging adult income & .04 & .03 & .05 & .03 \\
\hline Parent income & .05 & .02 & .05 & .02 \\
\hline Age & -.06 & .06 & -.07 & .06 \\
\hline Race $($ European American $=0$ ) & -.07 & .14 & -.07 & .13 \\
\hline Female $($ male $=0)$ & .02 & .11 & .11 & .15 \\
\hline Financial education*Gender & - & - & -.15 & .22 \\
\hline Adjusted $R^{2}$ & .11 & - & .11 & - \\
\hline
\end{tabular}

Note. $S E=$ standard error.

cial education was indeed associated with financial behavior $(\beta=.17, t=2.93, p=.004)$, as was impulsivity $(\beta=$ $-.25, t=-4.35, p<.001)$ and entitlement $(\beta=-.12, t=$ $-2.09, p=.04)$. Refer to Table 3 for the complete list of standardized partial slope coefficients (i.e., $\beta$ 's, standardized Beta coefficients). These findings suggest that, controlling for emerging adults' income, age, race, gender, materialism, and impulsivity, as well as their entitlement and their parents' income during childhood, those who report having received overt financial education during childhood were more likely to engage in healthy financial behaviors more often.

To test the second hypothesis, we ran the regression again with an interaction term between gender and overt financial education. This produced a significant model fit $(F(10,280)$ $=4.62, p<.001)$ which accounted for approximately $14 \%$ of the variance in frequency of healthy financial behaviors $\left(R^{2}=.14\right.$, Adjusted $\left.R^{2}=.11\right)$. As in the previous model, overt financial education $(\beta=.25, t=3.19, p=.002)$, impulsivity $(\beta=-.25, t=-4.38, p<.001)$, and entitlement $(\beta$ $=-.12, t=-2.03, p=.043$ ) were associated with financial behavior. Refer to Table 3 for the complete list of standardized partial slope coefficients. The interaction of gender and financial education was not significant $(\beta=-.15, t=-1.57$, $p=.12$ ).

As another post hoc exploration, we ran an independent sample $t$ test of financial education by gender to determine whether females had higher levels of healthy financial behaviors than males. The test was not significant, $t(434)=1.08, p=.28$, indicating that males and females did not differ in their frequency of healthy financial behaviors.

\section{Discussion}

In the current study, we examined whether retrospectively reporting overt financial education from parents during childhood was associated with a greater frequency of healthy financial management behaviors in emerging adulthood. Additionally, we examined whether this relationship was dependent on the gender of the emerging adult. The first hypothesis was supported: overt financial education was positively associated with a greater frequency of healthy financial management behaviors, while controlling for emerging adults' income, age, race, gender, materialism, and impulsivity, as well as their entitlement and caregiver income. This corroborates the family financial socialization model (Gudmunson \& Danes, 2011) in that overt financial socialization seems to relate to healthy financial behaviors. This study also offers support to the small body of previous research suggesting the relationship of overt financial instruction from parents on future financial behaviors (Jorgensen et al., 2017b; Norvilitis \& MacLean, 2010). It highlights the critical nature of formal and informal caregiver teaching moments to promote prosocial financial outcomes for emerging adults. 
However, the second hypothesis that the relationship between overt financial education and frequency of healthy financial management behaviors would be dependent on gender was not supported. This was surprising given that (a) females tend to have fewer financial experiences and opportunities outside the home than their male counterparts (Johnson \& Muse, 2017) and (b) previous research has suggested that parents may be more influential to females' financial learning than males' (Jorgensen \& Savla, 2010). It is possible that the moderation was not significant because of the outcome variable: financial behaviors. While many studies have found that males have more financial knowledge than females (e.g., Chambers et al., 2019; Danes \& Brewton, 2014; Fonseca et al., 2012), studies on whether males have better financial behaviors have produced mixed results (e.g., Hayhoe, Leach, Turner, Bruin, \& Lawrence, 2000; Henry, Weber, \& Yarbrough, 2001; Lyons, 2004; Worthy, Jonkman, $\&$ Blinn-Pike, 2010). Thus, future research should explore whether gender moderates the association between overt financial education during childhood and financial knowledge in emerging adulthood.

\section{Limitations and Future Research}

There are several limitations to this study. Though our model accounted for some of the variance in our outcome, there is still more work to be done to better understand emerging adults' healthy financial management behaviors. One limitation in our study which may contribute to this was that reports of overt financial education were retrospective and were obtained only from the emerging adults. Future research should use longitudinal designs to obtain more accurate data on overt financial education, and should collect reports from parents as well. Additionally, we were limited by the measures available to us; not all study variables were collected at the same wave. For example, entitlement was not available at wave 10 , and there is some evidence that various forms of entitlement may change over time in some individuals (Sessoms, Finney, \& Kopp, 2016).

The most severe limitation was the item used to measure overt financial education. Respondents were asked, "How would you describe how finances were communicated in your family? (check all that apply)." One of the available options was "My parents explicitly taught me about finances (e.g., credit cards, debt, budgeting, savings)." The three other options were "My parents usually argued about the finances," "We didn't talk much about finances but we learned (implicitly) from their examples," and "I didn't learn about finances from my parents implicitly or explicitly." The fact that respondents could check any number of boxes and that the four available responses are not mutually exclusive could be skewing the results. Future research should use a clearer measure of overt financial education. The dichotomous question used to explore overt financial education could not fully explore the nuanced differences parents may make in their financial socialization decisions with their children. It is possible that clearer, more nuanced measures would give valuable insights into potential gender moderation of not only overt financial teaching, but also other socialization methods such as modeling (Rosa et al., 2018) and experiential learning (LeBaron et al., 2019). Future measures should also examine financial teaching of specific financial concepts to further research on not just how but what parents should be teaching their children about finances (LeBaron et al., 2018a). Finally, future research should also explore financial socialization using a systems perspective, such as by investigating the influence of siblings on future financial behaviors.

It is perhaps encouraging that we found no significant moderation between gender and overt financial education on financial behavior. For example, emerging adult gender did not differentially impact associations between overt financial socialization and financial behaviors. However, due to the inconsistent results in the literature regarding gender as a moderator of parental financial education, it is important that future research explore this further, particularly with longitudinal, nationally representative data. Indeed, there is a general lack of exploration of gender as a feature of financial socialization, and we invite researchers to continue examining (a) whether/how males and females are socialized differently in regards to finances, (b) whether/how various financial socialization methods employed and financial topics taught predict differing outcomes for males and females, and (c) whether/how mothers and fathers tend to employ differing financial socialization techniques. For example, it would be interesting to test whether other forms of financial socialization besides explicit teaching (e.g., modeling [Rosa et al., 2018] or experiential learning [LeBaron et al., 2019] are moderated by gender). In a recent study, Agnew, Maras, and Moon (2018) found that, compared to no parent being present, if a female child's mother is present when the child spends her pocket money, the female child is $200 \%$ more likely to save some of 
her money. This effect was not found for male children. This suggests that parental financial monitoring may be more salient for female children than for male children.

Also, the gendered roles parents take on (e.g., if a father earns money and a mother does not) and the gendered attitudes parents hold may affect how they financially socialize their male and female children (e.g., both parents hold traditional gendered attitudes and assume their daughters will not be earners, therefore they explicitly teach their sons about finances but not their daughters). Parents' gender roles and gender attitudes should be explored in future research as components of financial socialization for males and females. Practitioners who work with parents and families should also be aware of family values and how those values influence any differences in what they teach their male and female children. Practitioners should work with parents so that children of both sexes are getting the financial education they need to be prepared for life on their own.

Future research should also explore the interaction between gender and SES as a feature of financial socialization. Newcomb and Rabow (1999) found that high social class was associated with lower parental expectations for working and saving, less concern from parents about grades and money, less belief in gender equality, less fear of finances, and greater desire for financial dependence, but only for females. However, Agnew and Cameron-Agnew (2015) found that financial socialization gender differences did not vary by socioeconomic status (SES). Future research should investigate further whether and how the role of gender in financial socialization differs by socioeconomic status (SES).

\section{Implications}

These findings have implications for financial educators and counselors, family life educators, policymakers, and parents. Previous research has shown that parents are the most influential source on children's financial learning (Pinto et al., 2005; Shim et al., 2010). The findings of the current study suggest that part of parents' influence is due to overt financial teaching, and that this influence extends into emerging adulthood. Thus, it is vital that financial counselors and educators involve parents to the greatest extent possible in teaching young people regarding finances (Hensley, 2015). Financial instruction will be more impactful when it is from someone close and trusted, such as parents
(Jorgensen et al., 2017b) as well as personalized based on financial attitudes and values (Jorgensen, Foster, Jensen, \& Vieira, 2017a). Additionally, parents can teach children over a long period of time. This repeated instruction over time may be more impactful than a one-and-done financial literacy course (Gudmunson \& Danes, 2011). Ideally, financial instruction should occur both at school and at home, with educators and parents communicating and collaborating (Hensley, 2015).

We invite family life educators, extension educators, and financial counselors with expertise in financial education, to encourage parents to overtly teach their children about finances. Financial education courses in secondary and postsecondary institutions could include a unit on how to teach children about finances so students are prepared to teach their own children in appropriate ways. Policymakers could aid in enhancing the financial literacy and capability of parents and in preparing parents to teach their children about finances by incentivizing educators to involve parents in financial education.

Finally, these findings have obvious implications for parents. As parents overtly teach their children about key financial principles, their children will be more prepared to engage in healthy financial behaviors in emerging adulthood. For example, parents could teach their children to divide the money they receive through allowance or earning money into three categories: save, spend, and give. Involving children in the process of family budgeting, based on their age and abilities, could help children understand better where the family's money is spent and how to make decisions regarding competing financial demands. By including children in some financial decisionmaking, children may be more likely to make their toys and clothes last longer and less likely to ask for money as frequently.

\section{References}

Agnew, S., \& Cameron-Agnew, T. (2015). The influence of consumer socialisation in the home on gender differences in financial literacy. International Journal of Consumer Studies, 39(6), 630-638. https://doi.org/10.1111/ijcs.12179

Agnew, S., Maras, P., \& Moon, A. (2018). Gender differences in financial socialization in the home-an exploratory study. International Journal of Consumer 
Studies, 42(3), 275-282. https://doi.org/10.1111/ijcs. 12415

Almenberg, J., \& Dreber, A. (2015). Gender, stock market participation and financial literacy. Economics Letters, 137, 140-142. https://doi.org/ 10.1016/j.econlet.2015.10.009

Beckman, L. J. (2014). Training in feminist research methodology: Doing research on the margins. Women \& Therapy, 164-177. https://doi.org/ 10.1080/02703149.2014.850347 37(1-2),

Beutler, I., \& Gudmunson, C. (2012). New adolescent money attitude scales: Entitlement and conscientiousness. Journal of Financial Counseling and Planning, 23(2), 18-31.

Blakemore, J. E. O., Berenbaum, S. A., \& Liben, L. S. (2013). Gender development. New York, NY: Psychology Press.

Borden, L. M., Lee, S., Serido, J., \& Collins, D. (2008). Changing college students' financial knowledge, attitudes, and behavior through seminar participation. Journal of Family and Economic Issues, 29(1), 23-40. https://doi.org/10.1007/s10834-007-9087-2

Britt, S. L., \& Huston, S. J. (2012). The role of money arguments in marriage. Journal of Family and Economic Issues, 33(4), 464-476. https://doi.org/ 10.1007/s10834-012-9304-5

Carroll, J. S. (2004). The comprehensive marriage preparation assessment survey (COMPASS) (C). Springville, UT: Persona LLC. [copyrighted and patent pending]

Chambers, R. G., Asarta, C. J., \& Farley-Ripple, E. N. (2019). Gender, parental characteristics, and financial knowledge of high school students: Evidence From multicountry data. Journal of Financial Counseling \& Planning, 30(1), 97-109. https://doi.org/10.1891/10523073.30.1.97

Chen, H., \& Volpe, R. P. (2002). Gender differences in personal financial literacy among college students. Financial Services Review, 11(3), 289-307.

Clarke, M., Heaton, M., Israelsen, C., \& Eggett, D. (2005). The acquisition of family financial roles and responsibilities. Family and Consumer Sciences Research Journal, 33(4), 321-340. https://doi.org/10.1177/ $1077727 \times 04274117$

Connell, R. W., \& Messerschmidt, J. W. (2005). Hegemonic masculinity: Rethinking the concept. Gender \& Society, 19(6), 829-859. https://doi.org/ $10.1177 / 0891243205278639$
Danes, S. M. (1994). Parental perceptions of children's financial socialization. Financial Counseling and Planning, 5(1), 127-149.

Danes, S. M., \& Brewton, K. E. (2014). The role of learning context in high school students' financial knowledge and behavior acquisition. Journal of Family and Economic Issues, 35(1), 81-94. https://doi.org/10.1007/s10834-013-9351-6

Danes, S. M., \& Haberman, H. R. (2007). Teen financial knowledge, self-efficacy, and behavior: A gendered view. Journal of Financial Counseling and Planning, $18(2), 48-60$.

Day, R. D., Coyne, S., Dyer, J., Harper, J., \& Walker, L. (2016). Flourishing families project: Survey of family life [Data file and code book]. Retrieved from https://familycenter.byu.edu/Pages/FFP.aspx

Deenanath, V., Danes, S. M., \& Jang, J. (2019). Purposive and unintentional family financial socialization, subjective financial knowledge, and financial behavior of high school students. Journal of Financial Counseling \& Planning, 30(1), 83-96. https://doi.org/10.1891/10523073.30.1.83

Dew, J. (2007). Two sides of the same coin? The differing roles of assets and consumer debt in marriage. Journal of Family and Economic Issues, 28(1), 89-104. https://doi.org/10.1007/s10834-006-9051-6

Dew, J. (2008). Debt change and marital satisfaction change in recently married couples. Family Relations, 57(1), 60-71. https://doi.org/10.1111/j.17413729.2007.00483.x

Dew, J., \& Xiao, J. J. (2011). The financial management behavior scale: Development and validation. Journal of Financial Counseling and Planning, 22(1), 43-59.

Else-Quest, N. M., \& Shibley Hyde, J. (2018). The psychology of women and gender: Half the human experience (9th ed.). Los Angeles, CA: Sage.

FINRA Investor Education Foundation. (2013). Financial capability in the United States: National Survey-EReport of findings from the 2012 National Financial Capability study. Washington, DC: Author. Retrieved from http://www.usfinancial capability.org/downloads/NFCS_2012_Report_Natl_ Findings.pdf

Fonseca, R., Mullen, K. J., Zamarro, G., \& Zissimopoulos, J. (2012). What explains the gender gap in financial literacy? The role of household 
decision-making. Journal of Consumer Affairs, 46(1), 90-106. https://doi.org/10.1111/j.1745-6606. 2011.01221.x

Garðarsdóttir, R. B., \& Dittmar, H. (2012). The relationship of materialism to debt and financial wellbeing: The case of Iceland's perceived prosperity. Journal of Economic Psychology, 33(3), 471-381. https://doi.org/10.1016/j.joep.2011.12.008

Gati, I., Osipow, S. H., \& Givon, M. (1995). Gender differences in career decision making: The content and structure of preferences. Journal of Counseling Psychology, 42(2), 204-216. https://doi.org/10.1037/00220167.42.2.204

Grinstein-Weiss, M., Spader, J. S., Yeo, Y. H., Key, C. C., $\&$ Freeze, E. B. (2012). Loan performance among lowincome households. Social Work Research, 36(4), 257270. https://doi.org/10.1093/swr/svs016

Gudmunson, C. G., \& Danes, S. M. (2011). Family financial socialization: Theory and critical review. Journal of Family and Economic Issues, 32(4), 644-667. https://doi.org/10.1007/s10834-011-9275-y

Hayhoe, C. R., Leach, L. J., Turner, P. R., Bruin, M. J., \& Lawrence, F. C. (2000). Differences in spending habits and credit use of college students. Journal of Consumer Affairs, 34(1), 113-133. https://doi.org/10.1111/j.17456606.2000.tb00087.x

Henry, R. A., Weber, J. G., \& Yarbrough, D. (2001). Money management practices of college students. College Student Journal, 35(2), 244-249.

Hensley, B. J. (2015). Enhancing links between research and practice to improve consumer financial education and well-being. Journal of Financial Counseling and Planning, 26(1), 94-101. https://doi.org/10.1891/10523073.26.1.94

Hibbert, J. R., Beutler, I. F., \& Martin, T. (2004). Financial prudence and next generation financial strain. Journal of Financial Counseling and Planning, 15(2), 51-59.

Hira, T. K. (2012). Promoting sustainable financial behaviour: Implications for education and research. International Journal of Consumer Studies, 36(5), 502507. https://doi.org/10.1111/j.1470-6431.2012.01115.x

Johnson, I. Y., \& Muse, W. B. (2017). Choice of academic major at a public research university: The role of gender and self-efficacy. Research in Higher Education, 58(4), 365-394. https://doi.org/10.1007/s11162-016-9431-1

Jorgensen, B. L., Foster, D., Jensen, J. F., \& Vieira, E. (2017a). Financial attitudes and responsible spending behavior of emerging adults: Does geographic location matter? Journal of Family and Economic Issues, 38(1), 70-83. https://doi.org/10.1007/s10834-016-9512-5

Jorgensen, B. L., Rappleyea, D. L., Schweichler, J. T., Fang, X., \& Moran, M. E. (2017b). The financial behavior of emerging adults: A family financial socialization approach. Journal of Family and Economic Issues, 38(1), 57-69. https://doi.org/10.1007/s10834015-9481-0

Jorgensen, B. L., \& Savla, J. (2010). Financial literacy of young adults: The importance of parental socialization. Family Relations, 59(4), 465-478. https://doi.org/10.1111/j.1741-3729.2010.00616.x

Kan, M. Y., \& Laurie, H. (2014). Changing patterns in the allocation of savings, investments and debts within couple relationships. The Sociological Review, 62(2), 335-358. https://doi.org/10.1111/1467-954X. 12120

Kim, J., \& Chatterjee, S. (2013). Childhood financial socialization and young adults' financial management. Journal of Financial Counseling and Planning, 24(1), 6179.

LeBaron, A. B., Hill, E. J., Rosa, C. M., \& Marks, L. D. (2018a). Whats and hows of family financial socialization: Retrospective reports of Millennials and their parents and grandparents. Family Relations, 67(4), 497509. https://doi.org/10.1111/fare.12335

LeBaron, A. B., Hill, E. J., Rosa, C. M., Spencer, T. J., Marks, L. D., \& Powell, J. T. (2018b). I wish: Multi-generational regrets and reflections on teaching children about money. Journal of Family and Economic Issues, 39(2), 220-232. https://doi.org/10.1007/ s10834-017-9556-1

LeBaron, A. B., Marks, L. D., Rosa, C. M., Marks, L. D., \& Hill, E. J. (2020). Can we talk about money? Financial socialization through parent-child financial discussion. Emerging Adulthood. https://doi:10.1177/ 2167696820902673

LeBaron, A. B., Rosa-Holyoak, C. M., Bryce, L. A., Hill, E. J., \& Marks, L. D. (2018c). Teaching children about money: Prospective parenting ideas from undergraduate students. Journal of Financial Counseling and Planning, 29(2), 259-271. https://doi.org/ 10.1891/1052-3073.29.2.259

LeBaron, A. B., Runyan, S., Jorgensen, B. L., Marks, L. D., Li, X., \& Hill, E. J. (2019). Practice makes perfect: Experiential learning as a method for financial 
socialization. Journal of Family Issues, 40(4), 435-463. https://doi.org/10.1177/0192513X18812917

Lusardi, A., \& Mitchell, O. S. (2008). Planning and financial literacy: How do women fare? (No. w13750). National Bureau of Economic Research. Retrieved from http:// www.nber.org/papers/w13750

Lusardi, A., Mitchell, O. S., \& Curto, V. (2010). Financial literacy among the young. Journal of Consumer Affairs, 44(2), 358-380. https://doi.org/10.1111/j.17456606.2010.01173.x

Lyons, A. C. (2004). A profile of financially at-risk college students. Journal of Consumer Affairs, 38, 56-80. https://doi.org/10.1111/j.1745-6606.2004.tb00465.x

Meisenbach, R. J. (2010). The female breadwinner: Phenomenological experience and gendered identity in work/family spaces. Sex Roles, 62(1-2), 2-19. https://doi.org/10.1007/s11199-009-9714-5

Newcomb, M. D., \& Rabow, J. (1999). Gender, socialization, and money. Journal of Applied Social Psychology, 29(4), 852-869. https://doi.org/10.1111/j.15591816.1999.tb02029.x

Norvilitis, J. M., \& MacLean, M. G. (2010). The role of parents in college students' financial behaviors and attitudes. Journal of Economic Psychology, 31(1), 55-63. https://doi.org/10.1016/j.joep.2009.10.003

Novak, S. P., \& Clayton, R. R. (2001). The influence of school environment and self-regulation on transitions between stages of cigarette smoking: A multilevel analysis. Health Psychology, 20, 196-207. https://doi.org/10.1037/0278-6133.20.3.196

Nye, P., \& Hillyard, C. (2013). Personal financial behavior: The influence of quantitative literacy and material values. Numeracy, 6(1), 3. https://doi.org/10.5038/19364660.6.1.3

Pahl, J. (1995). His money, her money: Recent research on financial organisation in marriage. Journal of Economic Psychology, 16(3), 361-376. https://doi.org/10.1016/0167-4870(95)00015-G

Pinto, M. B., Parente, D. H., \& Mansfield, P. M. (2005). Information learned from socialization agents: Its relationship to credit card use. Family and Consumer Sciences Research Journal, 33(4), 357-367. https://doi.org/10.1177/1077727X04274113

Rodman, H. (1972). Marital power and the theory of resources in cultural context. Journal of Comparative Family Studies, 3(1), 50-69. https://doi.org/ $10.3138 /$ jcfs. 3.1 .50
Rosa, C. M., Marks, L. D., LeBaron, A. B., \& Hill, E. J. (2018). Multigenerational modeling of money management. Journal of Financial Therapy, 9(2), 54-74. https://doi.org/10.4148/1944-9771.1164

Sapienza, P., Zingales, L., \& Maestripieri, D. (2009). Gender differences in financial risk aversion and career choices are affected by testosterone. PNAS Proceedings of the National Academy of Sciences of the United States of America, 106(36), 15268-15273. https://doi.org/10.1073/pnas.0907352106

Sessoms, J., Finney, S. J., \& Kopp, J. P. (2016). Does the measurement or magnitude of academic entitlement change over time? Measurement and Evaluation in Counseling and Development, 49(3), 243-257. https://doi.org/10.1177/0748175615625755

Shim, S., Barber, B. L., Card, N. A., Xiao, J. J., \& Serido, J. (2010). Financial socialization of first-year college students. Journal of Youth and Adolescence, 39(12), 14571470. https://doi.org/10.1007/s10964-009-9432-x

Smith, J. P., McArdle, J. J., \& Willis, R. (2010). Financial decision-making and cognition in a family context. The Economic Journal, 120(548), F363-F380. https://doi.org/10.1111/j.1468-0297.2010.02394.x

Wang, M.-T., \& Degol, J. (2013). Motivational pathways to STEM career choices: Using expectancyValue perspective to understand individual and gender differences in STEM fields. Developmental Review, 33(4), 304-340. https://doi.org/10.1016/ j.dr.2013.08.001

Watson, J. J. (2003). The relationship of materialism to spending tendencies, saving, and debt. Journal of Economic Psychology, 24(6), 723-739. https://doi.org/ 10.1016/j.joep.2003.06.001

Webley, P., \& Nyhus, E. K. (2006). Parents' influence on children's future orientation and saving. Journal of Economic Psychology, 27(1), 140-164. https://doi.org/10.1016/j.joep.2005.06.016

Worthy, S. L., Jonkman, J., \& Blinn-Pike, L. (2010). Sensation-seeking, risk-taking, and problematic financial behaviors of college students. Journal of Family and Economic Issues, 31(2), 161-170. https://doi.org/ 10.1007/s10834-010-9183-6

Xiao, J. J., Chatterjee, S., \& Kim, J. (2014). Factors associated with financial independence of young adults. International Journal of Consumer Studies, 38(4), 394-403. https://doi.org/10.1111/ijcs.12106 
Xiao, J. J., Chen, C., \& Sun, L. (2015). Age differences in consumer financial capability. International Journal of Consumer Studies, 39(4), 387-395. https://doi.org/10.1111/ijcs.12205

Yodanis, C., \& Lauer, S. (2007). Managing money in marriage: Multilevel and cross-national effects of the breadwinner role. Journal of Marriage and Family, 69(5), 1307-1325. https://doi.org/10.1111/j.17413737.2007.00449.x
Disclosure. The authors have no relevant financial interest or affiliations with any commercial interests related to the subjects discussed within this article.

Funding. The author(s) received no specific grant or financial support for the research, authorship, and/or publication of this article. 
Reproduced with permission of copyright owner. Further reproduction prohibited without permission. 